\title{
Development of a Photovoltaic Module Energy Ratings Methodology
}

B. Kroposki, L. Mrig NREL

C. Whitaker, J. Newmiller Endecon Engineering

Presented at the 13th NREL PV Program Review Meeting May 16-19, 1995 Lakewood, Colorado

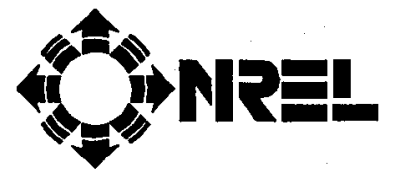

National Renewable Energy Laboratory 1617 Cole Boulevard Golden, Colorado 80401-3393 A national laboratory of the U.S. Department of Energy Managed by Midwest Research Institute for the U.S. Department of Energy under contract No. DE-AC36-83CH10093

Prepared under Task No. PV560103

May 1995 


\section{NOTICE}

This report was prepared as an account of work sponsored by an agency of the United States government. Neither the United States government nor any agency thereof, nor any of their employees, makes any warranty, express or implied, or assumes any legal liability or responsibility for the accuracy, completeness, or usefulness of any information, apparatus, product, or process disclosed, or represents that its use would not infringe privately owned rights. Reference herein to any specific commercial product, process, or senvice by trade name, trademark, manufacturer, or otherwise does not necessarily constitute or imply its endorsement, recommendation, or favoring by the United States government or any agency thereof. The views and opinions of authors expressed herein do not necessarily state or reflect those of the United States government or any agency thereof.

Available to DOE and DOE contractors from:

Office of Scientific and Technical Information (OSTI)

P.O. Box 62

Oak Ridge, TN 37831

Prices available by calling (615) 576-8401

Available to the public from:

National Technical Information Service (NTIS)

U.S. Department of Commerce

5285 Port Royal Road

Springfield, VA 22161

(703) $487-4650$ 


\title{
Development of a Photovoltaic Module Energy Ratings Methodology
}

\author{
B. Kroposki and L. Mrig \\ National Renewable Energy Laboratory \\ Golden, CO
}

\author{
C. Whitaker and J. Newmiller \\ Endecon Engineering \\ San Ramon, CA
}

\begin{abstract}
The National Renewable Energy Laboratory has begun work on developing a consensus-based approach to rating photovoltaic modules. This new approach was intended to address the limitations of the defacto standard module power rating at standard test conditions. Using technical input from a number of sources, and under the guidance of an industry-based technical review committee, the approach described in this paper was developed. The Module Energy Rating (MER) consists of 10 estimates of how much energy a single typical module of a particular type will produce in one day, one for each of 5 different weather/location combinations and 2 load-types. This paper presents an overview of the procedures required to generate an MER for any particular module type.
\end{abstract}

\section{INTRODUCTION}

The National Renewable Energy Laboratory (NREL) has begun work on developing a consensus-based approach to rating photovoltaic (PV) modules. This new approach is intended to address the limitations of the defacto standard module power rating at standard test conditions $\left(\mathrm{STC}^{1}\right)$. Using technical input from a number of sources, and under the guidance of an industry-based technical review committee, the approach described in this paper was developed.

This paper describes testing and computation procedures required to generate a Module Energy Rating (MER) for any particular module type. The MER consists of 10 estimates of how much energy a single typical module of a particular type will produce in one day; one for each of five different weather/location combinations and two load-types. Because reproduction of these exact testing conditions in the field or laboratory is not feasible, limited testing, modeling procedures and a predefined weather data set are specified.

The five weather/location combinations were chosen because they provide the basic range of environmental conditions anticipated for typical uses of PV

1 STC: $1000 \mathrm{~W} / \mathrm{m}^{2}$ total irradiance with an reference air mass 1.5 global spectrum and $25^{\circ} \mathrm{C}$ cell temperature. 
modules in the United States. This rating will also show differences in how module technologies perform in different types of weather.

Two load types are assumed, corresponding to the two most common loads connected to PV modules: maximum-power-tracking for grid-tied applications and fixed voltage for battery charging. For purposes of rating comparison, a fixed voltage per battery or daily battery voltage profile is assumed. The fixed-voltage value may be divided by the recommended number of modules and multiplied by the recommended number of batteries to obtain an appropriate fixed voltage for purposes of rating. If the manufacturer does not recommend its module for battery applications, then the modules need not be rated for fixed voltage. It is assumed that no charge regulation occurs; that is, the module operates at the specified voltage whenever there is sufficient sun.

The following sections describe the MER computations and the corresponding module inputs required to obtain the module-specific input data. The development of the five reference days and a sample MER are also described.

\section{MODULE ENERGY RATING COMPUTATION}

The MER consists of measuring module characteristics, defining sets of weather and load conditions, and estimating module performance under those conditions. This section describes the last of these three processes.

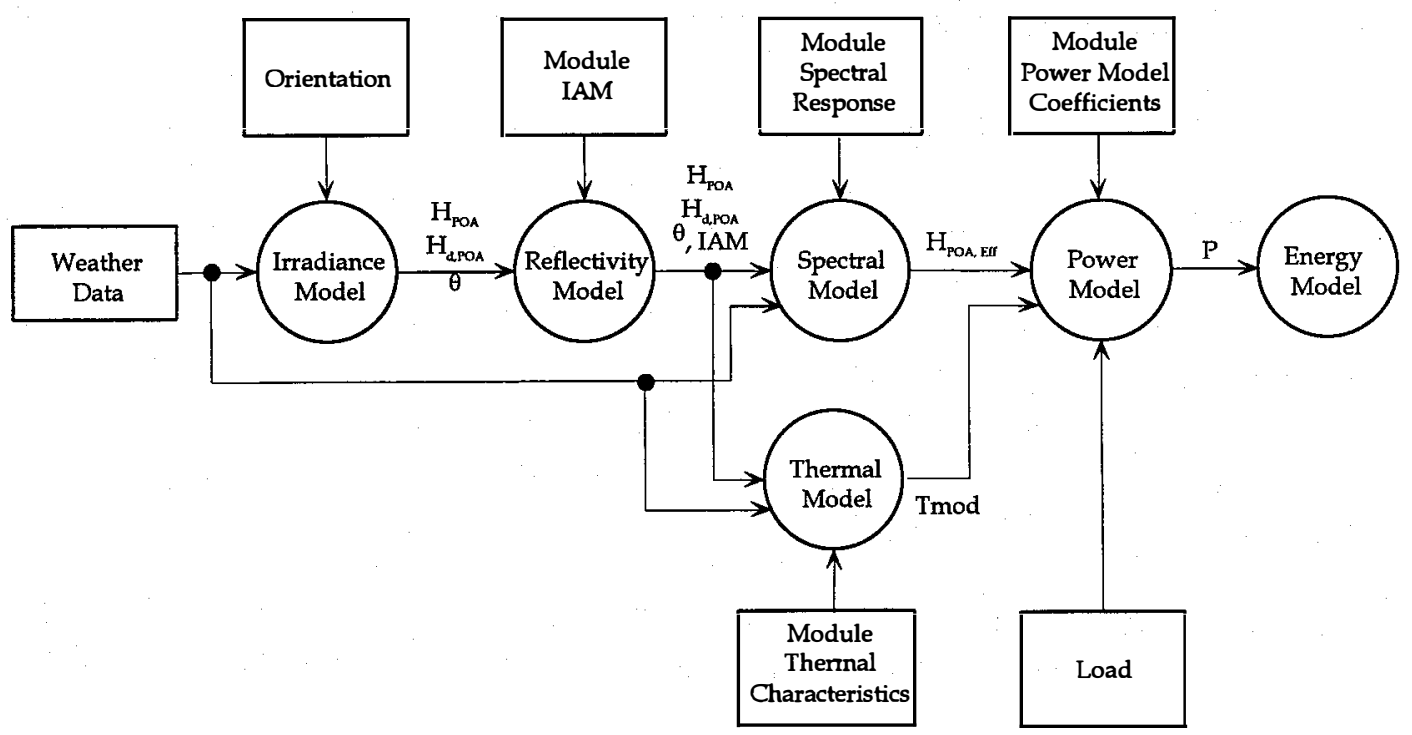

FIGURE 1. Methodology Flow Diagram 
Figure 1, shows conceptually the flow of data and the relationships between the various models. We will start at the right side of the diagram and work our way to the left. First, the algorithms used in each of the computational processes (the circles in Figure 1) are described. Next, the input variables (the rectangles in Figure 1) required for each process are presented.

\section{Energy Model}

Energy is computed from the daily power production curves by numerical integration according to the following formula (Euler integration):

$E=\Delta t \cdot \sum_{i=1}^{n} P_{i}$

where:

$\Delta t \quad=\quad$ Data sampling interval (h)

$P_{i}=$ DC power at the ith sample time (W)

This method is as accurate for daily power integration as trapezoidal integration would be, because the power at the beginning and end of the interval (midnight) is zero.

\section{Power Model}

The power output of the module is computed from the plane-of-array (POA) irradiance (adjusted for spectral and incidence-angle effects), the module temperature, and appropriate coefficients. The model gives power output for both maximum power and fixed voltage operating conditions. Several models are being considered for this methodology.

One model would be a simple linear-fit model that only depends on irradiance. Since this model does not incorporate spectral, thermal, or incidence angle effects, it would be easy to use and develop. But it may also be less accurate in predicting power output.

Another model for calculating power output uses the raw data supplied by a testing process. In this model, a matrix of power versus temperature and irradiance is developed. To obtain power values, linear interpolation is done on actual raw data. This method is especially good for non-linear devices.

Finally, translation equations may be used to determine power output. Translation equations translate an I-V curve taken at a reference irradiance and temperature to actual conditions. 


\section{Spectral Model}

The spectral model adjusts both the diffuse and direct irradiance incident on the plane-of-array surface as necessary, to account for variations in the incident spectrum under the assumed weather conditions. The resulting adjusted irradiances must be referenced to the flash-testing (solar simulator) spectrum and must account for the module spectral response. The general approach used is to compute the ratio of the actual effective irradiance to the reference effective irradiance, where an effective irradiance is the combined effect of a spectrum and a spectral response. This approach has been discussed by Emery et al.[1].

The spectral model that is intended to be used is implemented in the SEDES2 code [2]. This was derived from the SPCTRL2 model [3] with empirically derived enhancements for cloud cover.

\section{Thermal Model}

Another explicit input to several of the contemplated PV performance models is module temperature. Crystalline silicon module output varies by roughly $0.5 \% /{ }^{\circ} \mathrm{C}$ change in temperature. This module temperature coefficient is different for most thin-film devices. The temperature of a PV module depends on module material and construction, module mounting, ambient conditions (in order of decreasing importance: ambient temperature, irradiance, wind speed, wind direction, humidity, barometric pressure, elevation, etc.), and conversion efficiency (since solar power converted to electricity is unavailable for heating up the module). The model used in this methodology was developed by Fuentes [4].

\section{Reflectivity Model}

The reflectivity model uses the plane-of-array incident irradiance angle to obtain an incidence angle modifier (IAM) that accounts for reflection effects. This IAM can either be multiplied by the total plane-of-array irradiance $\left(H_{P O A}\right)$ to estimate the total absorbed plane-of-array irradiance for the thermal model, or included in the spectral model normalization computation.

\section{Irradiance Model}

The irradiance model transforms commonly available time-correlated irradiance and other weather measurements along with plane-of-array orientation into incidence angle, full-spectrum incident beam, and diffuse irradiance estimates using astronomical solar position equations and the Perez diffuse radiation model 
[5]. The steps in these computations are the determination of the true local solar time, computation of the local solar position, computation of the plane-of-array beam irradiance and incidence angle, and the evaluation of the Perez diffuse radiation model.

\section{REQUIRED INPUT DATA}

Input values designated with a star $\left(^{*}\right)$ are not strictly user inputs because they are defined by the MER specifications. They are, however, subject to change, such as updating the fixed voltage to reflect a new battery technology or a daily voltage profile. They might also be modified if the PV module is intended for a specific use not contemplated in the MER development.

\section{Module Load Type*}

The power output of any module depends on the voltage or current at which it is operated. Two load types representative of typical installations are specified:

The first load type is an ideal maximum power tracker. This load would change the voltage or current as necessary to maximize the power output of the module. This behavior would represent the ideal behavior of a grid-connected dc-to-ac power inverter, and represents the best energy production output obtainable from the module under the given environmental conditions.

The second load type is an ideal voltage source. This load would maintain a specified voltage at the module output regardless of the module's power producing capability. A fixed voltage is currently being used, but a daily voltage profile with fixed hourly voltage levels may be more representative of a batterycharging application.

\section{Location*}

The location is specified using the latitude, longitude and time zone. The latitude is expressed in degrees north of the equator (south is negative), the longitude is expressed in degrees east of Greenwich Observatory in England (west is negative), and the time zone is expressed in hours after Greenwich Mean Time (time zones for the United States are negative). 


\section{Environmental/Weather Data*}

The environmental/weather conditions include: time, date, global horizontal irradiance, direct normal irradiance, ambient temperature, dew point, relative humidity, barometric pressure, wind speed, cloud-cover modifiers, and atmospheric absorption spectra.

\section{Module Characteristics}

The PV module characteristic input parameters include: tilt angle from horizontal, azimuth angle, incident-angle modifier coefficients, spectral response function, nominal operating cell temperature (NOCT), efficiency at NOCT, and temperature and irradiance power coefficients. The spectral response and quantum efficiency of a module both quantify how a module responds to various wavelengths of incident light.

\section{REFERENCE DAY DEVELOPMENT}

This section describes the weather data and "reference days" selected for the MER methodology. Five reference days will be selected from the National Solar Radiation Database [6] as being representative of a variety of conditions within the United States. The five reference days will be selected based on the criteria listed in Table 1.

TABLE 1. Reference Day Criteria

\begin{tabular}{|l|l|l|l|l|l|}
\hline Profile & $\left.\begin{array}{l}\text { Irradiance } \\
(\text { Peak W/m }\end{array} \mathrm{m}^{2}\right)$ & $\begin{array}{l}\text { Daytime } \\
\text { High Temp }\left({ }^{\circ} \mathrm{C}\right)\end{array}$ & $\begin{array}{l}\text { Wind } \\
\text { Speed }\end{array}$ & $\begin{array}{l}\text { Relative } \\
\text { Humidity }\end{array}$ & $\begin{array}{l}\text { Cloud } \\
\text { Cover }\end{array}$ \\
\hline & & & & & \\
\hline Sunny-Hot & $>1000$ & $>35$ & Low & Low & $0 \%$ \\
\hline Sunny-Cold & $>900$ & $<0$ & Avg. & High & $<50 \%$ \\
\hline Cloudy-Hot & $<400$ & $>30$ & Avg. & High & $>50 \%$ \\
\hline Cloudy-Cold & 200 to 400 & $<0$ & High & High & $>90 \%$ \\
\hline Average-Nice & 800 to 900 & 20 & Avg. & Avg. & $30 \%$ \\
\hline
\end{tabular}

The table describes four extreme days and one average day. This set of conditions should be representative of the various types of weather found in the U.S. By seeing how much energy a module produces under a variety of weather conditions, a user should be able to estimate the module's performance in their location. 


\section{MODULE ENERGY RATING}

Using the procedure outlined in Figure 1 and as described above, for the reference days defined in Table 1, a module energy rating (MER) can be determined. The module energy rating will be a set of 10 numbers based on five different weather conditions and two different load conditions. An example of how this may be displayed on the back of a module is shown in Figure 2. This layout gives fictitious numbers for how much energy a module might produce under the different reference conditions. The peak-power energy output will be given in watt-hours (Wh), while the fixed-voltage energy will be given in amp-hours (Ah). This terminology should be useful to the end user and possibly system designer. A PV manufacturer may still also give the current, voltage, and power output of the module at STC, as is presently done.

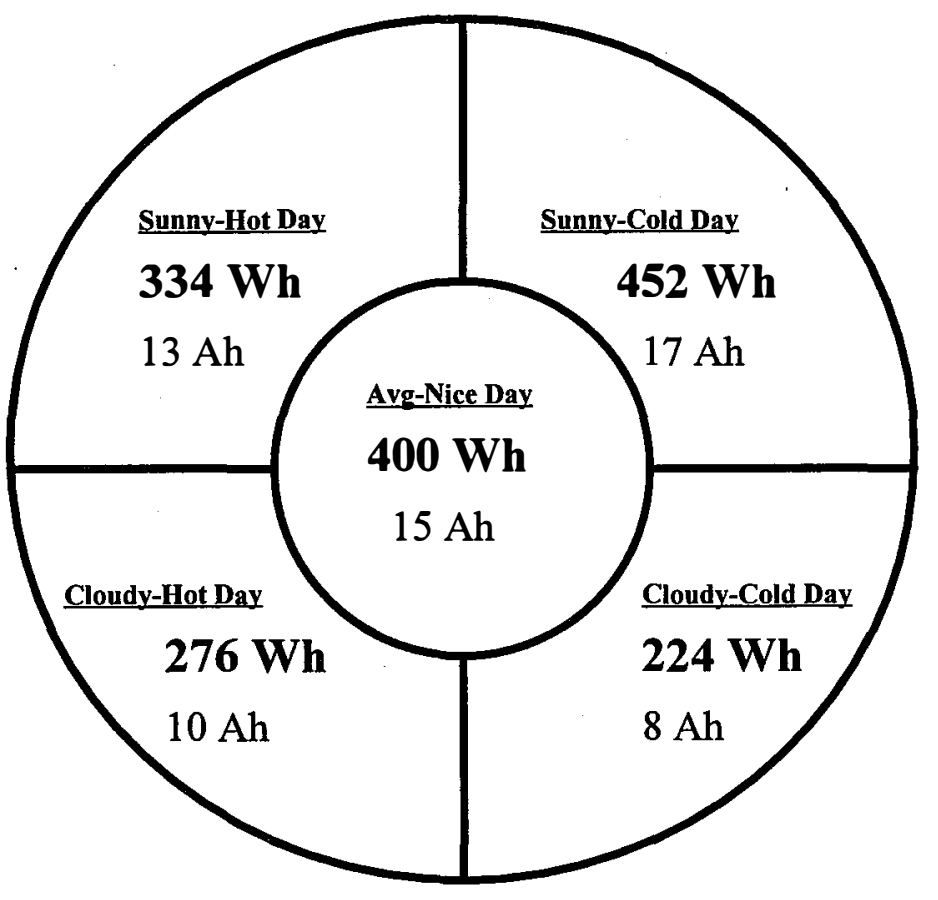

FIGURE 2. Sample Layout for Module Energy Rating [7]

\section{FUTURE WORK}

Continuing work is needed in several areas: model development, input data standardization, developing reference days for the rating procedure, and validation of the rating methodology. Work is currently being conducted in all of these areas. Development of new translation equations for power has been completed [8] and is currently being validated and compared with other models. Input 
parameters concerning; fixed voltages and voltage profiles for battery charging are still being discussed. Also, standard procedures for developing module performance characteristics (i.e. temperature and irradiance coefficients) are being developed. Development of the standard extreme and average days is also being researched. The validation of this rating methodology will take place once all parameters have been defined. The results of this research will be published as an NREL technical report which will fully describe the module energy rating methodology, the models and parameters used, and the procedures to follow in applying this method to any PV module.

\section{ACKNOWLEDGEMENTS}

The authors would like to acknowledge J. Anderson from Sunset Technologies. Jerry developed the idea of using the four extreme and one average reference day for energy comparison. He has also continued to develop new translation equations for PV module parameters. Thanks to D. Myers, who has helped with the meteorological research involved with this project. Additional thanks to $\mathrm{K}$. Emery, S. Rummel, Y. Caiyem, and L. Ottoson for testing modules for this project. Finally, thanks to R. DeBlasio, manager of the PV Module and System Performance and Engineering Project, for his continued support in the area of energy ratings. This work was supported by the U.S. DOE under contract No. DE-AC36-83CH10093.

\section{REFERENCES}

[1] Emery, K. et al., "Methods for measuring Solar Cell Efficiency Independent of Reference Cell or Light Source," Proc. 18th IEEE PV Specialist Conf., Las Vegas, NV, 1985, pp.623-628

[2] Nann, S. and S. Riordan, J. Appl. Meteorol. 30(1991) 447.

[3] Bird, R.E. and C. Riordan, J. Climate Appl. Meteorl. 25 (1986) 87.

[4] Fuentes, in: " A simplified thermal model for flat-plate photovoltaic arrays," Sandia Report 85-0330, Sandia National Laboratories, Albuquerque, NM, 1988.

[5] Perez, R., Stewart, R., Seals, R., Guertin, T., "The Development and Verification of the Perez Diffuse Radiation Model," Contractor Report SAND88-7030, Sandia National Laboratories, Albuquerque, NM, 1988.

[6] NCDC, "Solar and Meteorological Surface Observation Network", CD-ROM dataset, NCD, Ashville, NC, 1992

[7] Anderson, A. J., “An Energy Rating Concept for Photovoltaic Modules," Final Report for Task 2.0 of NREL Subcontract No. TAD-4-14166-01, 3/95.

[8] Anderson, A. J., "Photovoltaic Translation Equations: A New Approach," Final Report for Task 1.0 of NREL Subcontract No. TAD-4-14166-01, $11 / 94$. 